\title{
EVALUATING THE LEGIBILITY OF COMPLEX BUILDINGS: A QUANTITATIVE MODEL FOR INDOOR WAYFINDING
}

\author{
SARAH H. AHMED ${ }^{1,2}$, DINA S. TAHA ${ }^{1} \&$ ASMAA E. HASAN ${ }^{1}$ \\ ${ }^{1}$ Department of Architectural Engineering, Alexandria University, Egypt \\ ${ }^{2}$ Architectural Engineering Department, Pharos University in Alexandria, Egypt
}

\begin{abstract}
Wayfinding presents a significant aspect in architectural design since it is associated with the spatial organization and the legibility of indoor environments. It is believed that the physical characteristics of the indoor environment influence the performance of individuals in finding their way in complex settings. Navigation in such buildings can be a distressing process if the needed spatial information is not clearly presented to users; hence, it is important during the design phase to consider the factors that affect users' wayfinding performance. This paper examines these factors in indoor environments and focuses on the design variables that influence their legibility. Furthermore, it attempts to develop a quantitative evaluation model that assesses wayfinding in complex buildings in terms of their architectural design variables, through assigning weights of importance to these variables. For the purpose of implementing and testing the evaluation model, two case studies were conducted in shopping centers in Cairo, Egypt. The performance of users during the study was found to be consistent with the results of the evaluation model. This suggests that the assigned weights of the design variables were rather logical. These weights help in defining the design priorities for wayfinding: building configuration and its complexity are regarded as the first priority, followed by architectural differentiation, visual accessibility, and lastly, landmarks.
\end{abstract}

Keywords: architectural design, complex buildings, legibility, wayfinding performance.

\section{INTRODUCTION}

Physical environments have always been affecting individuals positively or negatively in both direct and indirect ways. A positive effect can be direct when the environment fulfills individuals' needs, on the other hand, it can be indirect, for instance, when environments create chances for desired social interactions [1]. As for the negative effects, the design of physical environments can directly cause discomfort which in some cases, may indirectly provoke unpleasant emotions as frustration or stress. One of the unfortunate experiences that negatively affect individuals is disorientation. The consequences of disorientation may range from being stressful or frustrating, as being late for an appointment, to being seriously dangerous as failing to find the emergency room in a hospital [2]. Being lost in a building was reported by several users as a frustrating experience since they fail to know their location nor locate their destination [2]. Such an unpleasant experience may result in the feeling of being trapped in a man-made maze [3].

Individuals usually face disorientation problems in environments or buildings that they perceive as complex. Buildings such as: museums, faculty campuses, convention centers, shopping centers, airports, and hospitals, are frequently referred to as complex. These buildings were found to challenge users' navigational abilities and test their spatial orientation which may result in navigational errors, stressful and frustrating conditions [2], [4]-[7].

Generally, the built environment has been referred to as complex in several occasions, for instance, Williams [8] defined it as: "The built environment, comprised of the physical structures and elements of man-made living, working, travelling and recreational environment, is a complex and multi layered system governed by a web of ecological, social, cultural, 
economic, and political relationships". This multi-layered system is believed to be composed of many interacting components that have the ability to generate a new quality of collective behavior through self-organization. These interacting components may be presented in the form of temporal, functional, and spatial structures [9], [10].

Indoor environments are one form of the built environment; therefore, it is valid to apply the definition of complex systems to indoor settings. Accordingly, a complex building may be defined as a large indoor environment with temporal, spatial, and functional variables.

In conclusion, a complex building is characterized by one or more of the following [5]:

(a) Being large in size, with a function that requires movement, or hosting a large number of people;

(b) Including multiple activities and different functions;

(c) Having a high density and a high level of diversity of occupancy and usage;

(d) Having multiple or fragmented ownership, management, or tenancy.

The study of the physical characteristics of indoor environments has been the focus of several researchers due to its proven impact on legibility, and hence, wayfinding [10], [11]. Individuals rely on environmental cues to orient themselves inside buildings and create an image of the setting [6], [12]. Therefore, in order to eliminate or reduce wayfinding problems, it is essential to understand the impact of the legibility of the physical environment and its elements [4]. In addition to, specifying all the physical environmental variables that contribute in easing spatial orientation and wayfinding of users [13]. Literature has mentioned multiple physical variables that affect legibility and indoor wayfinding. These include, but are not limited to the following: (1) plan configuration and complexity [10], [11], [14], (2) architectural differentiation [2], [12], [15], (3) landmarks [6], [14], [16], (4) visual accessibility [17]-[20], (5) circulation systems [3], [17], [21], (6) grouping of spaces [3], [21], (7) entrances [6], [21], and lastly (8) signs and maps [11], [22]-[24]. This research will focus on the architectural design variables that affect indoor wayfinding, while disregarding signs and maps, since they are graphic design variables and their existence does not overcome a poorly designed building [3].

\section{RESEARCH AIM AND OBJECTIVES}

The research aims to develop a quantitative evaluation model of the design characteristics of indoor physical environments as a means to enhance users' comprehension of complex buildings. This proves useful in facilitating the way-finding process and avoiding user's disorientation and frustrating experience. Within this aim, the objective of this research is to:

(a) Investigate the wayfinding cues perceived by users and their effectiveness,

(b) Formulate a quantitative evaluation model that assesses wayfinding in complex buildings in terms of their architectural design variables.

(c) Conclude the proper weights for the different variables.

Through the investigation of previous researches, it has been noticed that the evaluation of wayfinding in complex buildings is either qualitative for the whole building or quantitative for one or two architectural design variables [5], [19], [25].

This research attempts to examine thoroughly the relationships among all the variables and propose a weight for each one. Thus, create a quantitative model that allows an objective grading of buildings as a whole in relation to their architectural design variables. Furthermore, it will allow an objective comparison between two or more buildings regarding their legibility and ease of wayfinding. 


\section{METHODOLOGY AND RESEARCH METHODS}

This research utilized a multi-method approach to collect and analyze data, which included: literature research, a structured questionnaire, and multi-criteria decision methods. The implementation of the multi-method approach required choosing a workflow to benefit from the outcome of each method (Fig. 1).

\section{RESEARCH FRAMEWORK}

This research developed a framework for the purpose of creating a quantitative evaluation model for wayfinding in complex buildings. The framework is based on weighing the importance of the architectural design variables, designing a questionnaire, and eventually, creating an objective evaluation model.

\subsection{Weight of importance of architectural design variables}

A thorough review of literature facilitated setting the importance of architectural design variables affecting wayfinding in complex buildings. Firstly, the research examined the frequency of occurrence of each variable in a total of twenty references that were published between 1975 to 2019. Secondly, the importance of each variable was inspected as a means of grouping the important ones mentioned in these references (Fig. 2).

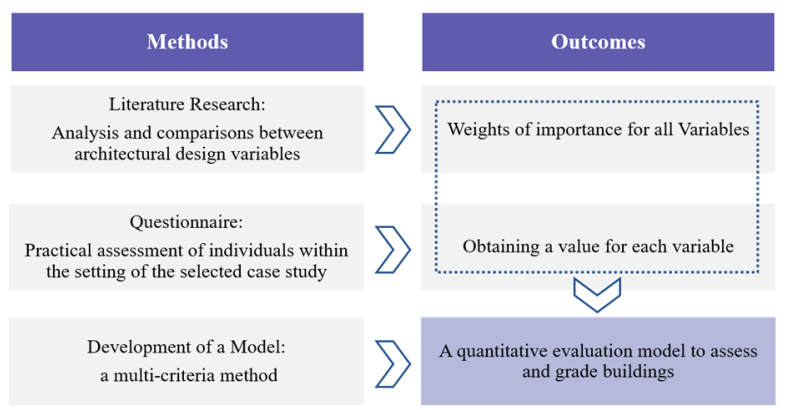

Figure 1: Workflow of main methods and their outcomes.

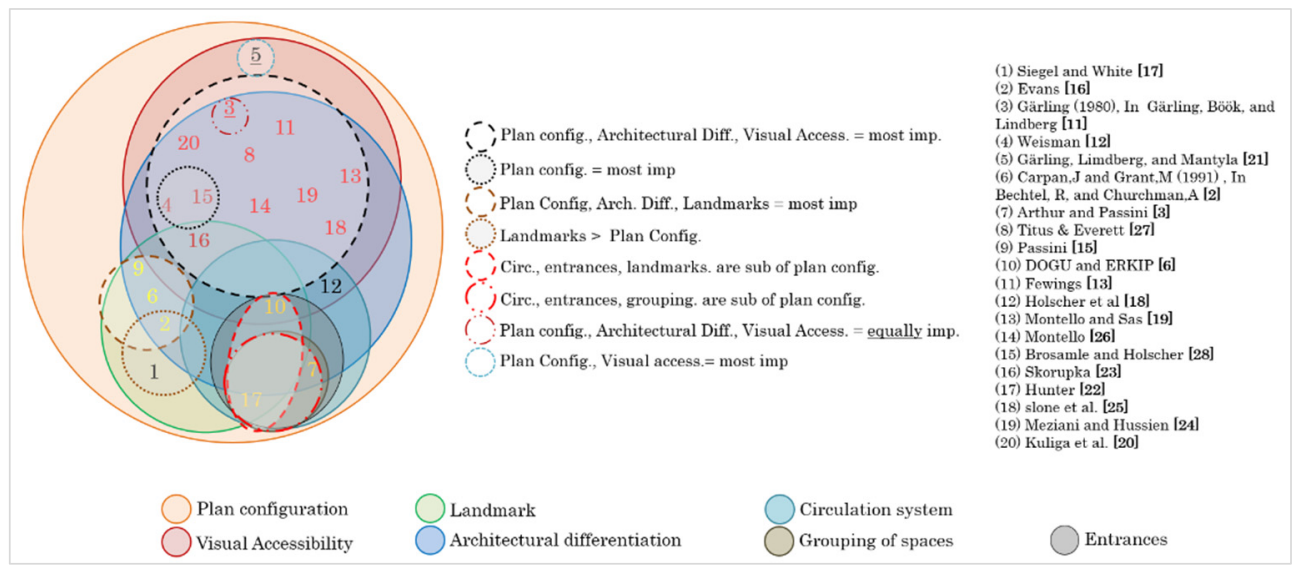

Figure 2: The occurrence and the importance of variables as mentioned in references. 
Finally, an analytical method was employed to compare between the different opinions regarding the importance of specific variables. Each variable is analyzed as follows:

Ten of the reviewed references agreed that Plan Configuration, Architectural Differentiation, and Visual Accessibility are the three most important variables [10]-[12], [18], [19], [23]-[27]. While Garling et al. [20] suggested that Plan Configuration and Visual Accessibility are the most effective ones. Plan Configuration was mentioned in all twenty reviewed references: eleven of which considered it as one of the most effective variables, while two references [11], [27], addition to Haq and Girotto [28] considered it as the most important one. Hence, Plan Configuration may be considered as the first and the most effective variable.

Three references considered Architectural Differentiation as one of the three most affecting variables along with Plan Configuration and Landmarks [2], [14], [15]. In addition to, ten references that regarded it as one of the three most important variables with Plan Configuration and Visual Accessibility [10]-[12], [18], [19], [23]-[27]. Architectural Differentiation was mentioned in seventeen of the reviewed references: thirteen of which considered it one of the three most effective variables. Hence, Architectural Differentiation is suggested to be the second most effective variable.

Ten References agreed that Visual Accessibility is one of the three most important variables [10]-[12], [18], [19], [23]-[27], along with Garling et al. [20] who regarded it as one of two most effective variables. Visual Accessibility was mentioned in fourteen of the reviewed references: eleven of which considered it one of the most effective variables. Hence, Visual Accessibility may be considered the third most effective variable.

Dogu and Erkip [4] suggested that Entrances, Circulation System, Landmarks are part of Plan Configuration and Complexity, whereas Arthur and Passini [3] suggested that Entrances and Circulation System are part of Plan Configuration and Complexity. Furthermore, Hunter [21] suggested that Entrances, Circulation System, Landmarks, \& Grouping of Spaces affect the legibility of Plan Configuration. Hölscher et al. [29] highlighted the importance of Circulation System as a wayfinding aid. Hence, Entrances and Circulation System may be considered as sub-variables to Plan Configuration and Complexity.

Arthur and Passini [3] and Hunter [21] suggested that Grouping of Spaces affect the legibility of plan layout and form. Hence, Grouping of Spaces may as well be considered a sub-variable to Plan Configuration and Complexity. Two references suggested that Landmarks variable is important for the legibility of Plan Configuration and wayfinding [6], [21], while another two references suggested that Landmarks are essential for wayfinding and even more important than Plan Configuration and its Complexity [15], [16]. Landmark variable was mentioned in six out of the twenty reviewed references: three of which considered it one of the important variables, while two regarded it as the most important variable. Hence, Landmarks may be considered the fourth most effective variable.

In summary, the results of the analysis suggest that plan configuration and complexity as the most important variable, followed in importance by architectural differentiation, visual accessibility, and lastly landmarks. Furthermore, plan configuration and complexity variable is proposed to include three sub-variables; entrances, circulation system, and grouping of spaces. This research will adopt these architectural variables as the criteria of the evaluation model. The normalized weight of importance of each variable is shown in Table 1.

\subsection{Design of the questionnaire}

A questionnaire of twenty-four questions was designed to gather data about wayfinding behavior of users, in addition to their perception and cognition of indoor environments. It 
Table 1: Proposed relative weights of the criteria.

\begin{tabular}{|c|c|c|c|c|c|}
\hline \multicolumn{3}{|c|}{ Plan config. and complexity } & Architectural & $\begin{array}{c}\text { Visual } \\
\text { accessibility }\end{array}$ & Landmarks \\
\cline { 1 - 2 } Entrances & $\begin{array}{c}\text { Circulation } \\
\text { systems }\end{array}$ & Grouping of spaces & differentiation & accol \\
\hline \multicolumn{2}{|c|}{0.40} & 0.30 & 0.20 & 0.10 \\
\hline
\end{tabular}

aims to practically assess buildings according to the wayfinding performance of their users. The format of the questionnaire is a combination of close-ended questions, open-ended questions and wayfinding tasks. The final form of the questionnaire is the result of an analysis of previous studies, such as Weisman [11], Lawton [30], and Dogu and Erkip [4]; in addition to a thorough review of the theories concerned with the design features that aid wayfinding.

The questionnaire is composed of four sections: The first section focuses on demographic data and identifies the familiarity, frequency, and purpose of visit for the questionnaire's respondents. The second section is concerned with the sense of direction and orientation of users in buildings. The third section focuses on the architectural features of the indoor environment and their legibility. In this section, each question refers to a specific architectural design variable. The fourth section of the questionnaire investigate the cognitive and wayfinding abilities of users through guiding tasks, pointing tasks, and cognitive mapping.

The questionnaire is designed to be handed out to users of selected buildings for study. Firstly, the answers of each question within the questionnaire is given a rank as a means to quantify the answers of the respondents (Table 2). Secondly, the results of the questionnaire are to be processed through simple additive weighting method (SAW). In this research, each architectural design variable represents an aspect, the alternatives are the respondents, while the attributes are the questions corresponding to the selected variable (Fig. 3). The value of each variable is determined by dividing the sum of values of the attributes with the number of respondents [31].

\subsection{Design of the evaluation model}

In order to objectively assess buildings according to all the architectural design variables and to grade buildings in comparison to each other, an AHP method was adopted. This method is based on hierarchically structuring the components of the problem, in addition to assigning numerical values to all the variables and factors that are taken into consideration. Applying AHP method requires setting a goal or objective, determining the criteria for evaluation, and finally choosing the alternatives [32], [33]. In this research, the objective is evaluating complex buildings in terms of wayfinding, while the criteria adopted is the list of the architectural design variables affecting indoor wayfinding. And at the third level, the

Table 2: Example of the weighted questionnaire answers.

\begin{tabular}{|c|c|c|c|}
\hline Question no. & Questionnaire answer & Rank & $\begin{array}{c}\text { Normalized } \\
\text { weight }\end{array}$ \\
\hline \multirow{3}{*}{10} & Very accurate & 4 & 1 \\
\cline { 2 - 4 } & Almost accurate & 3 & 0.75 \\
\cline { 2 - 4 } & Not entirely & 2 & 0.5 \\
\cline { 2 - 4 } & Not at all & 1 & 0.25 \\
\hline
\end{tabular}




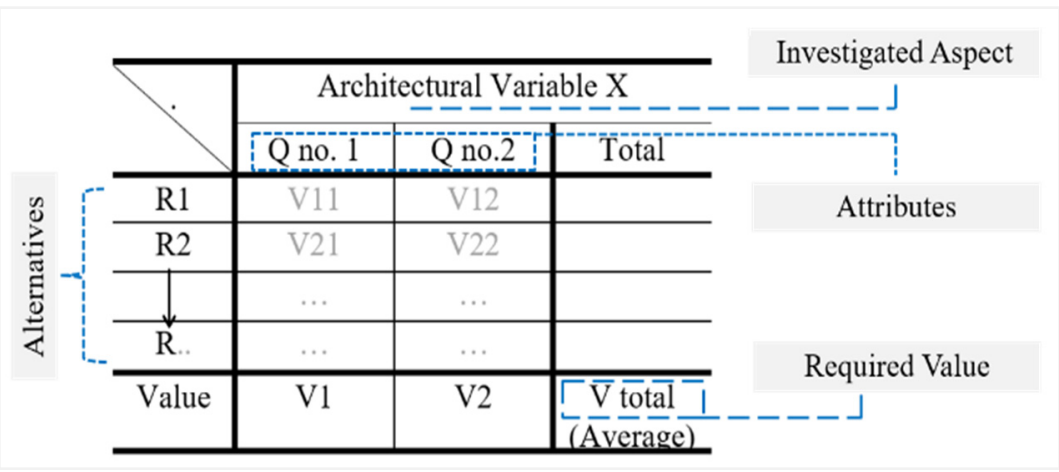

Figure 3: A simplified diagram of the applied SAW model.

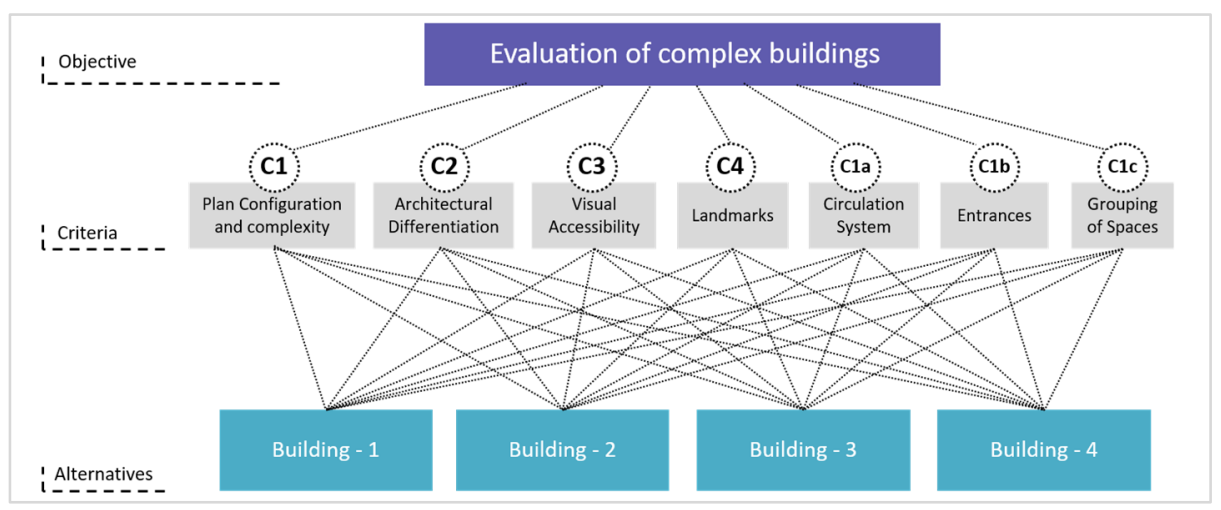

Figure 4: Hierarchal structure of the AHP evaluation model.

alternatives are the selected buildings for evaluation (Fig. 4). The model is designed to assess each building separately according to the list of criteria, in addition to comparing multiple buildings to each other and grade them.

The numeric values of each component in the model are obtained through the structured questionnaire and the previous analytic review of literature. The weight of the criteria was proposed in Table 1. While the value of each alternative in relation to the criteria is designated to be obtained from the questionnaire and quantified through SAW method. These values will then be processed using Super Decisions software which implements the AHP method. A simplified form of the input data on the software is shown in Fig. 5.

\section{EXPERIMENT AND RESULTS}

During this research, the investigation of wayfinding in complex buildings required selecting a building of two characteristics; first, a public building that would allow unconditional access to a diversity of users. Second, the existence and the variability of important aspects as familiarity, purpose of visit, and frequency of visit. These two characteristics are present in shopping centers; therefore, they are selected to be the focus of this research. The nature of shopping centers as an indoor-retail setting, places users in a complex environment where 


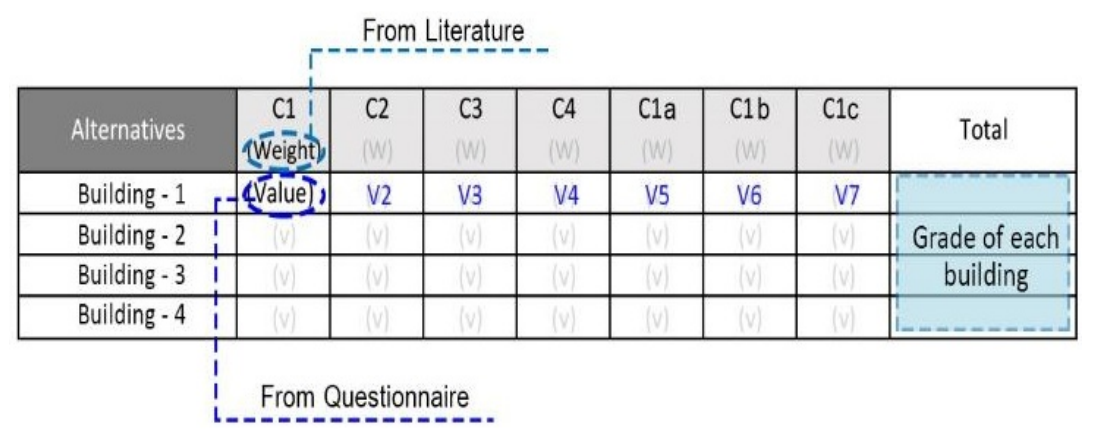

Figure 5: A simplified from of the AHP model.

they unintentionally perform several cognitive and wayfinding tasks [34]. Two shopping centers in Egypt are selected for study; Mall of Arabia (MoA) and Mall of Egypt (MoE).

\subsection{Description of case studies}

The first selected shopping center is MoA which is located on 26th July road in 6th October city. The two-storey building is designed around two inner courts with a gross building area (GBA) of 205,169 sq. meters. MoA was established in two phases; the first phase included a loop layout enclosing a large court with a fountain. The second phase was an expansion of a U-shaped layout that created another court named "The Park". The first phase represents the ground floor, while the second phase represents the underground floor and it is double the height of the first floor. The underground and the ground floors have two common atriums including the vertical circulation systems

The second shopping center is MoE, which is located on El-Wahat regional road in 6th October city. The building is of two stories and of a typical layout with a gross building area (GBA) of 226,222 sq. meters. MoA is designed on a rectangular layout with an open plaza at one side and a large atrium in its center named "The Valley". The building has a total of fifteen entry points; the main entrance accessed from the plaza, along with six entrances on the ground floor, and the other eight entrances on the first floor. The two floors are connected with several vertical circulation elements close to the entrances, in addition to escalators placed along the corridors.

\subsection{Implementation}

The questionnaire was handed out to a total of fifty respondents selected randomly. In MoA, twenty-five respondents were chosen at the atrium adjacent to entrance no.4 and no.5 (Fig. 6). While in MoE, another twenty-five respondents were chosen at a spot adjacent to the node between entrance no. E5 and "The Valley" (Fig. 6).

In both cases, and for all participants, the answers of section three of the questionnaire (concerning architectural features of the indoor environment) were weighted and quantified through SAW method in order to obtain the total value of each architectural variable. Tables 3 and 4 portray the feedback of each of the questionnaire's respondents on the different architectural variables in both case studies. For example, visual accessibility variable is investigated through questions no.12 and no.14. In case of respondent no.1 (R1), question 


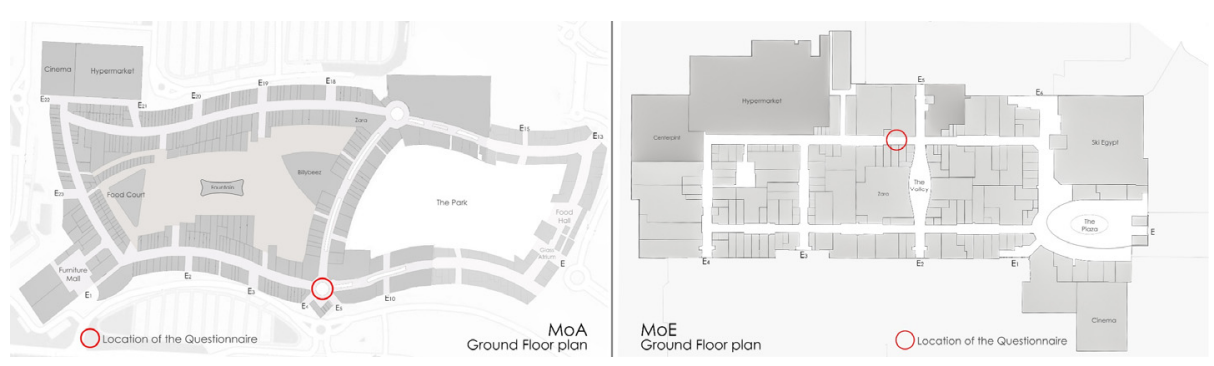

Figure 6: Location of the questionnaire on the ground floor plans of MoA and MoE. (Source: Mall of Arabia [35], Mall of Egypt [36], edited by researcher.)

Table 3: The weighted values of architectural variables for respondents at MoA.

\begin{tabular}{|l|c|c|c|c|c|c|c|}
\hline & \multicolumn{7}{|c|}{ Mall of Arabia- MoA } \\
\hline & C1 & C2 & C3 & C4 & C1a & C1b & C1c \\
\cline { 2 - 9 } & $\begin{array}{c}\text { Plan config } \\
\text { and } \\
\text { complexity }\end{array}$ & $\begin{array}{c}\text { Architectural } \\
\text { differentiation }\end{array}$ & $\begin{array}{c}\text { Visual } \\
\text { accessibility }\end{array}$ & Landmarks & $\begin{array}{c}\text { Circulation } \\
\text { systems }\end{array}$ & Entrances & $\begin{array}{c}\text { Grouping } \\
\text { of spaces }\end{array}$ \\
\cline { 2 - 9 } & Q-22, Q-11 & Q-11, Q-16 & Q-12, Q-14 & Q-18 & Q-17, Q-20 & Q-13 & Q-15 \\
\hline R1 & 0.375 & 0.175 & 0.625 & 0.060 & 0.750 & 0.500 & 0.250 \\
\hline R2 & 0.250 & 0.175 & 0.375 & 0.060 & 0.625 & 0.250 & 0.500 \\
\hline R3 & 0.750 & 0.175 & 0.750 & 0.250 & 0.750 & 0.750 & 0.250 \\
\hline R4 & 0.625 & 0.175 & 0.625 & 0.250 & 0.750 & 0.750 & 0.500 \\
\hline R5 & 0.750 & 0.300 & 0.625 & 0.250 & 0.750 & 0.750 & 0.250 \\
\hline R6 & 0.375 & 0.300 & 0.500 & 0.060 & 0.500 & 0.500 & 0.500 \\
\hline R7 & 0.625 & 0.300 & 0.625 & 0.250 & 0.500 & 0.500 & 0.500 \\
\hline R8 & 0.750 & 0.300 & 0.750 & 0.250 & 0.750 & 0.750 & 0.500 \\
\hline R9 & 0.625 & 0.300 & 0.625 & 0.250 & 0.750 & 0.750 & 0.500 \\
\hline R10 & 0.250 & 0.175 & 0.375 & 0.060 & 0.500 & 0.250 & 0.500 \\
\hline R11 & 0.750 & 0.175 & 0.750 & 0.250 & 0.750 & 0.750 & 0.750 \\
\hline R12 & 0.750 & 0.300 & 0.625 & 0.250 & 0.750 & 0.750 & 0.500 \\
\hline R13 & 0.375 & 0.300 & 0.500 & 0.060 & 0.500 & 0.500 & 0.500 \\
\hline R14 & 0.375 & 0.300 & 0.500 & 0.060 & 0.500 & 0.500 & 0.750 \\
\hline R15 & 0.625 & 0.300 & 0.625 & 0.250 & 0.750 & 0.750 & 0.500 \\
\hline R16 & 0.375 & 0.175 & 0.625 & 0.060 & 0.750 & 0.500 & 0.250 \\
\hline R17 & 0.250 & 0.175 & 0.375 & 0.060 & 0.625 & 0.250 & 0.750 \\
\hline R18 & 0.625 & 0.175 & 0.625 & 0.250 & 0.750 & 0.750 & 0.500 \\
\hline R19 & 0.375 & 0.175 & 0.625 & 0.060 & 0.750 & 0.500 & 0.750 \\
\hline R20 & 0.625 & 0.300 & 0.625 & 0.250 & 0.750 & 0.750 & 0.250 \\
\hline R21 & 0.250 & 0.175 & 0.375 & 0.060 & 0.625 & 0.250 & 0.750 \\
\hline R22 & 0.625 & 0.175 & 0.625 & 0.250 & 0.750 & 0.750 & 0.500 \\
\hline R23 & 0.375 & 0.300 & 0.500 & 0.060 & 0.500 & 0.500 & 0.750 \\
\hline R24 & 0.750 & 0.300 & 0.625 & 0.250 & 0.750 & 0.750 & 0.750 \\
\hline R25 & 0.750 & 0.175 & 0.750 & 0.250 & 0.750 & 0.750 & 0.590 \\
\hline Value & 0.530 & 0.235 & 0.585 & 0.166 & 0.675 & 0.590 & 0.750 \\
\hline
\end{tabular}


Table 4: The weighted values of architectural variables for respondents at MoE.

\begin{tabular}{|l|c|c|c|c|c|c|c|}
\hline & \multicolumn{7}{|c|}{ Mall of Egypt - MoE } \\
\cline { 2 - 8 } & $\begin{array}{c}\text { Plan config } \\
\text { and } \\
\text { complexity }\end{array}$ & $\begin{array}{c}\text { Architectural } \\
\text { differentiation }\end{array}$ & $\begin{array}{c}\text { Visual } \\
\text { accessibility }\end{array}$ & Landmarks & $\begin{array}{c}\text { Circulation } \\
\text { systems }\end{array}$ & Entrances & $\begin{array}{c}\text { Grouping of } \\
\text { spaces }\end{array}$ \\
\cline { 2 - 9 } & Q-22, Q-11 & Q-11, Q-16 & Q-12, Q-14 & Q-18 & Q-17, Q-20 & Q-13 & Q-15 \\
\hline R26 & 0.500 & 0.300 & 0.750 & 0.250 & 0.750 & 0.750 & 0.500 \\
\hline R27 & 0.250 & 0.300 & 0.750 & 0.250 & 1.000 & 1.000 & 0.250 \\
\hline R28 & 0.500 & 0.300 & 0.875 & 1.000 & 0.875 & 1.000 & 0.250 \\
\hline R29 & 0.375 & 0.175 & 0.750 & 0.250 & 0.750 & 0.750 & 0.250 \\
\hline R30 & 0.500 & 0.750 & 0.750 & 1.000 & 0.750 & 0.750 & 0.250 \\
\hline R31 & 0.500 & 0.175 & 0.875 & 0.250 & 0.750 & 1.000 & 0.250 \\
\hline R32 & 0.500 & 0.175 & 0.750 & 0.250 & 0.750 & 0.750 & 0.750 \\
\hline R33 & 0.250 & 0.175 & 0.750 & 0.060 & 0.750 & 0.750 & 0.250 \\
\hline R34 & 0.750 & 0.300 & 0.875 & 0.250 & 0.875 & 0.750 & 0.500 \\
\hline R35 & 0.375 & 0.175 & 0.750 & 0.250 & 0.750 & 0.750 & 0.250 \\
\hline R36 & 0.625 & 0.300 & 0.875 & 0.250 & 1.000 & 1.000 & 0.500 \\
\hline R37 & 0.625 & 0.175 & 0.750 & 0.250 & 0.750 & 0.750 & 0.250 \\
\hline R38 & 0.625 & 0.300 & 0.750 & 1.000 & 0.750 & 0.750 & 0.500 \\
\hline R39 & 0.500 & 0.300 & 0.750 & 0.250 & 0.750 & 0.750 & 0.250 \\
\hline R40 & 0.625 & 0.300 & 0.875 & 0.060 & 1.000 & 0.750 & 0.500 \\
\hline R41 & 0.625 & 0.300 & 0.875 & 0.250 & 1.000 & 0.750 & 0.750 \\
\hline R42 & 0.250 & 0.175 & 0.750 & 0.060 & 0.750 & 0.750 & 0.500 \\
\hline R43 & 0.750 & 0.300 & 0.750 & 0.250 & 0.875 & 0.750 & 0.500 \\
\hline R44 & 0.750 & 0.300 & 0.750 & 0.060 & 1.000 & 0.750 & 0.750 \\
\hline R45 & 0.500 & 0.300 & 0.750 & 0.060 & 0.750 & 0.750 & 0.250 \\
\hline R46 & 0.500 & 0.875 & 0.750 & 0.250 & 0.750 & 0.750 & 0.750 \\
\hline R47 & 0.750 & 0.300 & 0.750 & 0.250 & 0.875 & 0.750 & 0.500 \\
\hline R48 & 0.625 & 0.300 & 0.750 & 1.000 & 0.750 & 0.750 & 0.500 \\
\hline R49 & 0.500 & 0.300 & 0.750 & 0.250 & 0.750 & 0.750 & 0.250 \\
\hline R50 & 0.625 & 0.300 & 0.875 & 0.250 & 1.000 & 0.750 & 0.750 \\
\hline Value & 0.535 & 0.306 & 0.785 & 0.408 & 0.830 & 0.790 & 0.440 \\
\hline
\end{tabular}

no.12 was answered as "hard" which corresponds to a weighted value of 0.5 . While question no.14 was answered as "almost easy" which corresponds to a weighted value of 0.75 . Therefore, the weighted value of visual accessibility variable for R1 is the average of both values, which is equal to 0.625 . The exact method is applied for respondents R1 to R25 and the average sum of their values is calculated to obtain a total weighted value of visual accessibility variable in MoA which is equal 0.585 . In the same manner, the rest of the architectural variables are calculated for both case studies.

The results of the previous method are utilized as the input data for the AHP evaluation model. For each case study, the value of each variable is multiplied by its relative weight 
(Table 1) and the added to other variables. For example, the calculations of MoA are as follows:

C1 Plan config. and complexity (C1a, C1b, C1c): $\quad$ (Avg. 0.530,0.675,0.590,0.750) x 0.4

C2 Architectural Differentiation:

$(0.235) \times 0.3$

C3 Visual Accessibility:

$(0.585) \times 0.2$

$+$

C4 Landmarks:

$(0.166) \times 0.1$

0.4314

The Super Decisions software implements the previous method of calculation, in addition to comparing between different case studies and prioritizing them. The input data of MoA (Table 3) and MoE (Table 4) is inserted in the model, along with the suggested weight of variables in Table 1. The evaluation model calculates the total value of both shopping centers in respect of all the architectural variables, in addition to ranking them in relation to each other. Table 5 represents the final form and results of the evaluation model.

Table 5: The results of the evaluation model as produced by Super Decisions software.

\begin{tabular}{|l|c|c|c|c|c|c|}
\hline Alternatives & Priorities & Totals & $\begin{array}{c}\text { Architectural } \\
\text { differentiation }\end{array}$ & Landmarks & $\begin{array}{c}\text { Plan } \\
\text { configuration }\end{array}$ & $\begin{array}{c}\text { Visual } \\
\text { accessibility }\end{array}$ \\
\cline { 4 - 7 } & & 0.3 & 0.1 & 0.4 & 0.2 \\
\hline MoA & 0.4380 & 0.4314 & 0.235000 & 0.166000 & 0.568330 & 0.585000 \\
\hline MoE & 0.5620 & 0.5536 & 0.306000 & 0.408000 & 0.660000 & 0.785000 \\
\hline
\end{tabular}

\section{FINDINGS AND DISCUSSION}

The results of the evaluation model show that the calculated total value of MoA is 0.4314 , while, MoE is 0.5536 (Table 5). These results suggest that MoE is better than MoA in respect to the architectural variables affecting wayfinding. In order to check the validation of these results, they are compared with the performance of respondents in the last section of the questionnaire. In MoA, only $28 \%$ of the respondents succeeded in giving directions while $64 \%$ of MoE respondents were able to give directions successfully. During the task of locating an unseen goal $4 \%$ of MoA respondents were able to complete the task, on the other hand, $64 \%$ completed the task successfully in MoE. Lastly, when asked to locate themselves on a map, only $16 \%$ of MoA respondents succeeded, while $56 \%$ of the respondent at MoE located themselves correctly. These percentages show that the wayfinding and cognitive performance of users in $\mathrm{MoE}$ is significantly higher than users of MoA. Moreover, the respondents of both shopping centers reported their need for a printed map to assist them in finding their way, with a $64 \%$ in MoA and $44 \%$ in MoE. However, when asked about their wayfinding experience, $48 \%$ of MoA respondents reported facing difficulties every time they visit the building, while only $16 \%$ faced the same issue in MoE. These findings support the final results of the evaluation model.

Furthermore, disorientation and wayfinding difficulties experienced in MoA can be linked to the spatial properties and the design of the building. Through the results of the questionnaire, it can be deduced which architectural variables had a negative effect on wayfinding in each case. For instance, when comparing the calculated value of entrances variable in both MoA and MoE, the value of MoA is remarkably lower than the latter. The entrances of MoA were of a great number which may lead to confusion and uncertainty. 
Moreover, the layout of the building does not strengthen the existence of these entrances, an issue that led to the placement of large digits on the exterior of each entrance and large signs in the interior. On the other hand, the main entrance of MoE has a strong identity and the other entrances are placed on a grid which facilitates finding their location. Both shopping centers scored low values of architectural differentiation. The analysis of the two buildings shows that, apart from the different ceiling designs, there is no clear distinctiveness or differentiation. Furthermore, almost none of the respondents reported noticing the differentiation of the ceilings. The lack of landmarks in MoA affected the wayfinding performance of its users and it is reflected on its calculated value. When asked, the respondents did not recall perceiving any landmarks in the buildings and they failed to select any elements that they could utilize as a landmark. Instead, some of them utilized one of the two atriums or a shop overlooking them as a landmark. In the case of MoE, users were able to perceive designed landmarks as the water element located in "The Valley". Some users relied on information desks as physical cues, while others reported relying on an anchor entertainment zone. Generally, MoE offers more elements and zones that can be regarded as landmarks, therefore its concluded landmark value is higher than MoA. Similarly, the value of visual accessibility in MoE was found to be higher than MoA. Such difference may be explained by the existence of the large atrium in the center and the corridors of the first and second floor which overlook the ground floor creating a visual connection between floors. Generally, evidence suggests that MoE eases wayfinding when compared to MoA and such suggestion is consistent with the results of the proposed evaluations model.

\section{CONCLUSION}

This research proposed a quantitative model to evaluate complex buildings in general and shopping centers in particular in respect to wayfinding. The consistency between the recorded performance of users and the results of the evaluation model, suggests that the weighted values of the architectural variables are rather logical. These weights help in defining the design priorities for wayfinding. Building configuration and its complexity are regarded as the first priority when designing buildings for wayfinding, followed by architectural differentiation, visual accessibility, and lastly, landmarks. Generally, the suggested evaluation model can provide an objective judgement when assessing wayfinding in complex buildings. The model develops a grade for buildings, in addition to providing a quantitative comparison between two or more buildings in respect to their spatial characteristics and physical elements. This model can be employed to assess and enhance existing buildings for better wayfinding. Furthermore, it can provide an insight into the effectiveness of each architectural design variable from the perspective of users. Such an insight can be employed in the early planning of complex buildings as a means to optimize their design for wayfinding.

Future research should aim to conduct the designed questionnaire and implement the evaluation model on a larger sample of users of shopping centers. Furthermore, it is recommended to apply the framework of this research on different typologies of complex buildings in order to investigate the validity of the evaluation model and the proposed weights of the architectural variables on a wider scale.

\section{REFERENCES}

[1] Zimring, C.M., Stress and the designed environment. J Soc Issues, 37, pp. 145-171, 1981.

[2] Bechtel, R.B, \& Churchman, A., Handbook of Environmental Psychology, John Wiley \& Sons, Inc.: New York, 2002. 
[3] Arthur, P. \& Passini, R., Wayfinding: People, Signs, and Architecture, McGraw-Hill Ryerson: Ontario, 1992.

[4] Dogu, U. \& Erkip, F., Spatial factors affecting wayfinding and orientation: A case study in a shopping mall. Environmet Behav, 32, pp. 731-755, 2000.

[5] Cabinet Office, Public safety in complex and built environments, London, 2007.

[6] Dalton, R.C., Spiers, H. \& Holscher, C., Navigating Complex Buildings: Cognition, Neuroscience and Architectural Design, 2015.

[7] Vilar, E., Teixeira, L., Rebelo, F., Noriega, P. \& Teles, J., Using environmental affordances to direct people natural movement indoors. Work, 41, pp. 1149-1156, 2012.

[8] Williams, L.M., Getting To Know The Built Environment As A Complex System, Toronto, 2013.

[9] Meyers, R.A., Encyclopedia of Complexity and Systems Science, Springer, 2009.

[10] Gärling, T., Böök, A. \& Lindberg, E., Spatial orientation and wayfinding. The designed environment: A conceptual analysis and some suggestions for postoccupancy evaluation. J Archit Plann Res, 3, pp. 55-64, 1986.

[11] Weisman, J., Evaluating architectural legibility: Way-finding in the built environment. Environ Behav, 13, pp. 189-204, 1981.

[12] Fewings, R., Wayfinding and airport terminal design. J Navig, 54, pp. 177-184, 2001.

[13] Andre, A.D., Human orientation and wayfinding in airport passenger terminals. Transp Res Rec, pp. 25-32, 1991.

[14] Passini, R., Wayfinding design: Logic, application and some thoughts on universality. Des Stud, 17, pp. 319-331, 1996.

[15] Evans, G.W., Environmental cognition. Psychol Bull, 88, pp. 259-287, 1980.

[16] Siegel, A.W. \& White, S.H., The development of spatial representations of large-scale environments. Adv Child Dev Behav, 10, pp. 9-55, 1975.

[17] Holscher, C., Meilinger, T., Vrachliotis, G., Brosamle, M. \& Knauff, M., Up the down staircase : Wayfinding strategies in multi-level buildings. $J$ Environ Psychol, 26, pp. 284-299, 2006.

[18] Montello, D.R. \& Sas, C., Human factors of wayfinding in navigation. International Encyclopedia of Ergonomics and Human Factors, 2006.

[19] Kuliga, S.F. et al., Exploring individual differences and building complexity in wayfinding: The case of the Seattle Central Library. Environ Behav, pp. 1-44, 2019.

[20] Garling, T., Limdberg, E. \& Mantyla, T., Orientation in buildings: Effects of familiarity, visual access, and orientation aids. J Appl Psychol, 68, pp. 177-186, 1983.

[21] Hunter, S., Design Resources, New York, 2010.

[22] Skorupka, A., Do you know your way? A mixed-method study on the use of virtual environments in wayfinding research. Movement and Orientation in Built Environments: Evaluating Design Rationale and User Cognition, eds S. Haq, C. Holscher \& S. Torgrude, SFB/TR 8 Spatial cognition: Bremen, pp. 21-33, 2008.

[23] Meziani, R. \& Hussien, H.A., A study on the space layout and configuration of shopping malls in relation to pedestrian movement behavior - Case of UAE. Int Rev Spat Plan Sustain Dev, 5, pp. 53-65, 2017.

[24] Slone, E., Burles, F., Robinson, K., Levy, R.M. \& Iaria, G., Floor plan connectivity influences wayfinding performance in virtual environments. Environ Behav, 47, pp. 1024-1053, 2015.

[25] Montello, D.R., The contribution of space syntax to a comprehensive theory of environmental psychology. International Space Syntax Symposium, Istanubl, pp. 1$12,2007$. 
[26] Titus, P.A. \& Everett, P.B., The consumer retail search process: A conceptual model and research agenda. J Acad Mark Sci, 23, pp. 106-119, 1995.

[27] Brosamle, M. \& Holscher, C., Architects seeing through the eyes of building users? A qualitative analysis of design cases. Spatial Cognition in Architectural Design Anticipating User Behavior, Layout Legibility, and Route Instructions in the Planning Process, eds T. Barkowsky, Z. Bilda, C. Holscher \& G. Vrachliotis, Transregional Collaborative Research Center: Melbourne, pp. 8-13, 2007.

[28] Haq, S. \& Girotto, S., Ability and intelligibility: Wayfinding and environmental cognition in the designed environment. Proceedings of the 4th International Space Syntax Symposium, pp. 1-68, 2003.

[29] Hölscher, C., Meilinger, T., Vrachliotis, G., Brösamle, M. \& Knauff, M., Up the down staircase: Wayfinding strategies in multi-level buildings. $J$ Environ Psychol, 26, pp. 284-299, 2006.

[30] Lawton, C.A., Strategies for indoor wayfinding: The role of orientation. J Environ Psychol, 16, pp. 137-145, 1996.

[31] Kasim, M., Ibrahim, H. \& Batanieh, M., Multi-criteria decision making methods for determining computer preference index. JICT, pp. 137-48, 2011.

[32] Saaty, T.L., The analytic hierarchy process: Decision making in complex environments. Quantitative Assessment in Arms Control, ed. R. Avenhaus, Plenum Press: New York, pp. 285-308, 1984.

[33] Zuraidi, S.N.F., Rahman, M.A.A. \& Akasah, Z.A., A study of using AHP method to evaluate the criteria and attribute of defects in heritage building. International Conference on Civil and Environmental Engineering, eds Y.F. Huang, K.W. Tan, L. Ling \& K.H. Leong, vol. 65, E3S Web of Conferences: Kuala Lumpur, pp. 1-14, 2018.

[34] Titus, P.A. \& Everett, P.B., Consumer wayfinding tasks, strategies, and errors: An exploratory field study. Psychol Mark, 13, pp. 265-90, 1996.

[35] Mall of Arabia, Mall map. www.mallofarabia.com.eg/en/mall/map. Accessed on: 8 Apr. 2020.

[36] Mall of Egypt, Mall Guide, Store locator. www.mallofegypt.com/Maps/indexmallofegypt.html?lng=en\#. Accessed on: 8 Apr. 2020. 